\title{
Sequences in the NS5A protein of hepatitis C virus and the serum alanine aminotransferase response to interferon therapy in Japanese patients
}

K Nagayama, N Enomoto, N Izumi, M Kurosaki, Y Miyasaka, H Watanabe, J Itakura, C-H Chen, J Tazawa, Y Hoshino, T Ikeda, F Marumo, C Sato

Second Department of Internal Medicine, Faculty of Medicine, Tokyo Medical and Dental University, 1-5-45 Yushima, Bunkyo-ku, Tokyo, Japan, 113-8519

K Nagayama N Enomoto

M Kurosaki

Y Miyasaka

H Watanabe

J Itakura

C-H Chen

F Marumo

Department of Gastroenterology and Hepatology, Musashino Red Cross Hospital, 1-26-1 Kyonan-cho, Musashino city, Tokyo, Japan, 180-8610

N Izumi

Department of Internal Medicine, Tsuchiura Kyodo General Hospital, 14-7 Manabe-shinmachi, Tsuchiura city, Ibaraki, Japan, 300-0053

J Tazawa

Second Department of Internal Medicine, Yokosuka Kyosai General Hospital, 22-7 Yonegahama-dori, Yokosuka city,

Kanagawa, Japan, 238-0011

Y Hoshino

T Ikeda

Department of Health

Science, Faculty of Medicine, Tokyo

Medical and Dental

University, 1-5-45

Yushima, Bunkyo-ku,

Tokyo, Japan, 113-8519

C Sato

Correspondence to:

Dr N Enomoto.

nenomoto.med2@med.

tmd.ac.jp

Accepted for publication 12 December 2000

\section{Abstract}

Background and aims-Chronic hepatitis $\mathrm{C}$ is a slowly progressive disease and eventually causes hepatocellular carcinoma in many patients. Although interferon (IFN) therapy has been used for viral eradication, its success rate is only about $30 \%$. In patients in whom it has failed (nonresponders), there are several patterns of serum alanine aminotransferase (ALT) values, and detection of serum HCV-RNA during and after IFN therapy and improved long term prognosis were reported in patients whose serum ALT values were normalised by IFN therapy even if $\mathrm{HCV}$ viraemia persisted. The present study sought to clarify the virological characteristics contributing to these differences. Methods-Complete or partial length dominant sequences of hepatitis $C$ virus genotype 1b (HCV-1b) were determined by direct sequencing. Firstly, the complete sequences of $\mathrm{HCV}-1 \mathrm{~b}$ genomes were determined in six non-responders; three showed normalisation of serum ALT values during IFN- $\alpha$ therapy and the other three did not. Subsequently, the amino acid residues that were different in the two groups were further analysed retrospectively in another 82 patients.

Results-Comparison of the sequences suggested an association between amino acids 2154-2172 of $\mathrm{HCV}-1 \mathrm{~b}$ and serum ALT normalisation. A retrospective analysis of 82 patients revealed that the number of amino acid substitutions in this region was the only statistically significant variable associated with ALT normalisation (odds ratio $31.0 ; 95 \%$ confidence interval 5.0-286) in multivariate analyses. Conclusions-A HCV genomic region that correlates with the ALT response to IFN therapy appears to be present in virologically IFN ineffective patients.

(Gut 2001;48:830-835)

Keywords: hepatitis C virus; alanine aminotransferase; biochemical responder; transient responder, NS5A protein

Hepatitis $\mathrm{C}$ virus (HCV) is a single stranded RNA virus consisting of approximately 9500 nucleotides. ${ }^{1-3}$ Persistent HCV infection causes chronic hepatitis $\mathrm{C}$, which may develop into liver cirrhosis and hepatocellular carcinoma (HCC) over $20-30$ years in some patients. ${ }^{4}$ To date, interferon (IFN) alone or combined with ribavirin is the only curative therapy for chronic hepatitis C. ${ }^{5}$ However, its efficacy is as low as $30 \%$ in patients with HCV genotype $1 \mathrm{~b}$ infection, the predominant genotype in Japan, even when a sufficient amount of IFN is administrated. ${ }^{6} \mathrm{HCV}$ viraemia is not cleared in more than half of $\mathrm{HCV}-1 \mathrm{~b}$ infected patients, and they continue to be at risk for disease progression. As a result, clinical and virological analyses targeted at these patients is important.

A complete responder (CR) to IFN therapy is defined as a patient negative for serum HCV-RNA, as assayed by reverse transcription-polymerase chain reaction at six months after the final IFN administration. ${ }^{5} \mathrm{~A}$ patient who does not meet this criterion is defined as a non-responder (NR). However, NRs can be divided into subgroups according to serum alanine aminotransferase (ALT) values and/or the presence of HCV-RNA. Figure 1 schematically shows the course of ALT values in NRs. In fig $1 \mathrm{~A}$, ALT values are persistently abnormal throughout the course of treatment. This group is defined as biochemical non-responders (bNRs) in this study. In fig $1 \mathrm{~B}$, while ALT values transiently normalise during IFN therapy (usually within eight weeks), they return to abnormal levels within six months after cessation of IFN administration. This group is defined as biochemical transient responders (bTRs). In fig 1C, ALT values normalise during IFN therapy and are sustained for more than six months after treatment. This group is a special subgroup of bTR and can be included in bTR, but we define this patient group as biochemical responders (BRs). These different courses between bTR and BR appear to have clinical correlations. Kasahara et al reported that patients with the clinical course shown in fig $1 \mathrm{~B}$ or $1 \mathrm{C}$ have a lower risk of developing $\mathrm{HCC}^{7}$ compared with those showing the course demonstrated in fig 1A. Nishiguchi et al also reported that reduced ALT values as a result of IFN therapy led to a decreased incidence of HCC. ${ }^{8}$ It has also been reported that the incidence of HCC declines in

Abbreviations used in this paper: IFN, interferon; ALT, alanine aminotransferase; HCV, hepatitis $C$ virus; HCV-1b, HCV genotype 1b; HCC, hepatocellular

carcinoma; CR, complete responder; NR,

non-responder; BR; biochemical responder; TR, transient responder; ISDR, interferon sensitivity determining region; NCR, non-coding region; PCR, polymerase chain reaction; ARE, ALT response related element; HCV-2a, HCV genotype 2a; HCV-2b, HCV genotype $2 \mathrm{~b}$; CTL, cytotoxic T lymphocytes. 

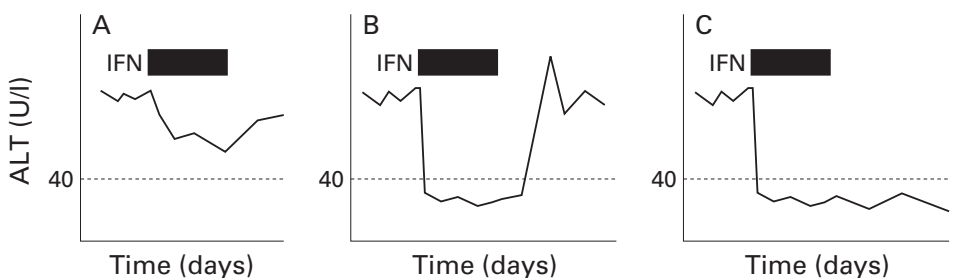

Figure 1 Schematic diagram of the typical clinical courses of serum alanine aminotransferase (ALT) values during and after interferon (IFN) therapy. (A) Patient without ALT normalisation (biochemical non-responder (bNR)); (B) patient with ALT normalisation and subsequent flare up (biochemical transient responder (bTR)); and (C) patient with ALT normalisation and sustained normal ALT values after IFN therapy (biochemical responder (BR)).

Table 1 Clinical backgrounds of the initial six patients

\begin{tabular}{|c|c|c|c|c|c|c|}
\hline & \multicolumn{3}{|c|}{ Normalised ALT group } & \multicolumn{3}{|c|}{ Abnorml ALT group } \\
\hline & $\begin{array}{l}\text { Patient } \\
1\end{array}$ & $\begin{array}{l}\text { Patient } \\
2\end{array}$ & $\begin{array}{l}\text { Patient } \\
3\end{array}$ & $\begin{array}{l}\text { Patient } \\
4\end{array}$ & $\begin{array}{l}\text { Patient } \\
5\end{array}$ & $\begin{array}{l}\text { Patient } \\
6\end{array}$ \\
\hline Age (y) & 51 & 42 & 61 & 63 & 53 & 58 \\
\hline $\operatorname{Sex}(M / F)$ & $\mathrm{F}$ & $M$ & M & $\mathrm{F}$ & $M$ & $M$ \\
\hline $\begin{array}{l}\text { Pretreatment serum ALT } \\
\text { (IU/1) }\end{array}$ & 98 & 93 & 129 & 56 & 92 & 106 \\
\hline $\begin{array}{l}\text { ALT at final IFN session } \\
(\text { IU } / 1)\end{array}$ & 10 & 10 & 24 & 47 & 109 & 49 \\
\hline Platelet count $\left(\times 104 / \mathrm{mm}^{3}\right)$ & 13.8 & 17.4 & 20.9 & 19.2 & 10.5 & 15.5 \\
\hline $\operatorname{HCV}-\mathrm{RNA}(\mathrm{Meq} / \mathrm{ml})^{\star}$ & 11 & $<0.5$ & 11 & 7.6 & 15 & 10 \\
\hline \multicolumn{7}{|l|}{ Histological findings } \\
\hline Activity & 2 & 1 & 2 & 2 & 2 & 3 \\
\hline Fibrosis & 3 & 1 & 2 & 3 & 3 & 3 \\
\hline
\end{tabular}

${ }^{\star}$ HCV-RNA levels were determined by a branched chain DNA assay.

†Histological findings were classified according to the criteria described by Enomoto and colleagues. ${ }^{12}$

ALT, alanine aminotransferase; HCV, hepatitis C virus; IFN, interferon.

BR patients. ${ }^{6}$ This reduction in HCC incidence implies a better long term prognosis in these patients.

We recently reported that patients who showed transient serum HCV-RNA disappearance during and shortly after (less than six months) IFN therapy (we define such patients as virological transient responders (vTRs)) showed a lower incidence of HCC compared with patients who did not experience HCVRNA disappearance during and after IFN therapy (virological non-responders (vNRs)) (N Izumi et al, unpublished observation). As a possible explanation for these observations, Poynard et al showed that IFN therapy significantly reduced the grade of inflammatory activity and stage of fibrosis, ${ }^{9}$ resulting in a lowering of the risk of developing HCC. In this study, we attempted to elucidate the viral determinant(s) associated with bTRs because it may be related to the preferable prognosis of IFN therapy.

In our previous studies we have shown that IFN resistant patients can be predicted by the substitution number in the IFN sensitivity determining region (ISDR) ${ }^{10}{ }^{11}$ but virological factors concerning differences in the pattern of ALT fluctuation in NRs have not been determined. Thus we analysed the complete genomes of $\mathrm{HCV}$ to elucidate any virological factors that may be associated with different patterns of ALT fluctuation.

\section{Patients and methods}

PATIENTS

We studied 88 patients with chronic $\mathrm{HCV}-1 \mathrm{~b}$ infection. All were positive for serum anti-HCV antibodies (third generation assay) and serum
HCV-RNA of genotype-1b. ${ }^{12}{ }^{13}$ Serum HCVRNA levels were determined by a branched chain DNA assay ${ }^{14}$ (Quantiplex HCV-RNA, Chiron, Emeryville, California, USA). The limit of detection of the assay was 0.5 million genome equivalents $/ \mathrm{ml}$. Patients were negative for serum HBs antigen, anti-HBc antibodies, and antinuclear antibodies, and had no other causes of hepatitis, including excessive alcohol intake or hepatotoxic drugs. Liver biopsies were performed in all patients, and the presence of chronic active hepatitis was confirmed histologically. Written informed consent was obtained from each patient for liver biopsy, and the study protocol conformed to the ethical guidelines of the 1975 Declaration of Helsinki. Institutional approval was obtained.

Initially, full length sequences of $\mathrm{HCV}$ were determined in six patients. All six received IFN therapy but were found to be NRs. Each serum sample was obtained just before the start of IFN therapy. Among them, three showed persistently elevated serum ALT values during and after IFN therapy (similar to the clinical course shown in fig 1A) (elevated ALT group), and in the other three, serum ALT values normalised within eight weeks after the start of IFN therapy, similar to the clinical course shown in fig $1 \mathrm{~B}$ (normalised ALT group). The clinical backgrounds of the patients are shown in table 1 . The six full length sequences were aligned, and amino acid (for the coding region) or nucleotide (for the non-coding region (NCR)s) usage was compared between the two groups. Only residues in which amino acid (or nucleotide) usages were completely different were regarded as being possibly associated with the divergent clinical courses.

Subsequently, the sequences of selected residues were determined in another 28 patients, and only regions in which amino acid usage was significantly different between the elevated and normalised ALT groups were further analysed. Finally, the relationship between the amino acid sequence and clinical course was retrospectively analysed in 82 patients.

\section{RNA EXTRACTION}

Experimental methods were conducted as described previously. ${ }^{15} 16$ Serum RNA was extracted by the acid-guanidium-phenolchloroform method. Briefly, $150 \mu$ of serum were mixed with $700 \mu \mathrm{l}$ of ISOGEN (Wako Pure Chemical Industries, Osaka, Japan), and the aqueous phase was extracted once with $140 \mu \mathrm{l}$ of chloroform. RNA was isopropanol precipitated with $20 \mu \mathrm{g}$ of glycogen (Boehringer Mannheim, Manheim, Germany) as a carrier. The resultant RNA was washed once with ethanol and finally dissolved in $10 \mu \mathrm{l}$ of water and stored at $-70^{\circ} \mathrm{C}$ until use.

cDNA SYNTHESIS

A $5 \mu$ reaction volume contained $1 \mu \mathrm{l}$ of the RNA solution, $50 \mathrm{U}$ of reverse transcriptase (M-MLV Reverse Transcriptase; Life Technologies Inc., Gaithersburg, Maryland, USA) and its accompanying buffer, 10 units of RNase 


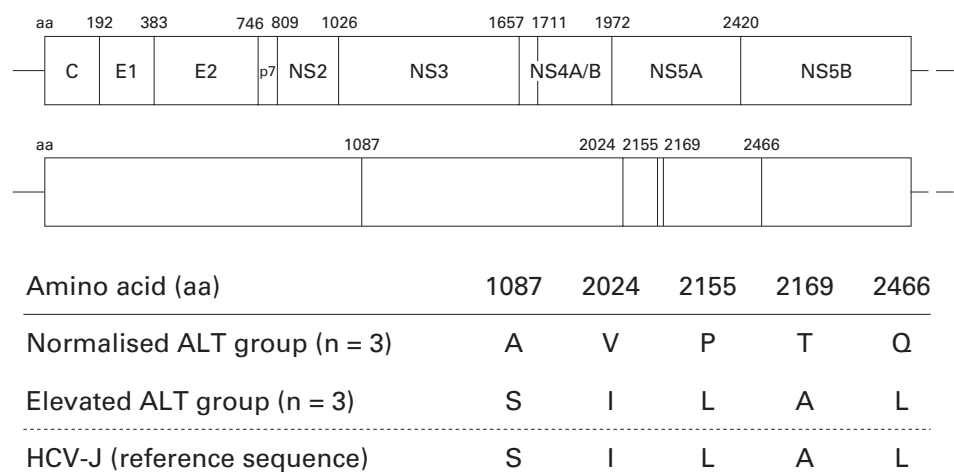

Figure 2 Codons for which the encoded amino acid are different between the two groups. The upper column shows the architecture of the hepatitis $C$ virus (HCV) polyprotein and the lower column shows the distribution of the amino acid residues. Amino acid usages in each group and HCV-F are shown in the lowermost table. Amino acids are described in the single letter code.

\section{Results}

COMPARISON OF THE FULL LENGTH HCV SEQUENCES

Codons for which the encoded amino acids were completely different between the two groups are shown in fig 2. Complete amino acid usage differences were observed in only five residues. Serine, isoleucine, leucine, alanine, and leucine were used in amino acids $1087,2024,2155,2169$, and 2466, respectively, in the elevated ALT group; these were the same as those in HCV-J. However, alanine, valine, proline, threonine, and glutamine, respectively, were used in the normalised ALT group. No differences in nucleotide usage were observed in NCRs.

Subsequently, amino acid sequences around these five residues were determined in 28 NRs. Among them, 16 belonged to the elevated ALT group (bNR) and 12 to the normalised ALT group (bTR). Amino acid usages were significantly different between the two groups at amino acids 2155 ( $\mathrm{p}=0.022$ by $\chi^{2}$ test, proline for bTR and leucine for bNR) and 2169 ( $p=0.050$ by Fisher's exact test, threonine for bTR and alanine for bNR). However, no significant difference was seen at amino acids 1087 ( $p>0.99$ by Fisher's exact test, alanine for bTR and serine for bNR), 2024 ( $p=0.11$ by Fisher's exact test, valine for bTR and isoleucine for $b N R)$, or $2466\left(p=0.13\right.$ by $\chi^{2}$ test, glutamine for bTR and leucine for bNR). Besides these residues, amino acid usage was also different at amino acid 2171 ( $\mathrm{p}=0.044$ by Fisher's exact test, non-leucine for bTR and leucine for bNR). Thus the predicted amino acid sequences in the region from amino acids 2154 to 2172 appeared to show a correlation with the course of serum ALT values during IFN therapy. We propose to name this region the ALT response related element (ARE). HCV from the normalised ALT group had more amino acid substitutions in this region compared with HCV-J while HCV from the elevated ALT group had fewer. From these preliminary results, we explored the relationship between the course of ALT values during and after IFN therapy and the sequence of the ARE in larger numbers of patients.

ANALYSIS OF THE RELATIONSHIP BETWEEN THE ALT RESPONSE AND THE ARE

In total, 82 patients were included in the analysis. All patients received IFN therapy and were judged to be NRs. Among the 82 patients, 25 belonged to the elevated ALT group (bNR) and 57 to the normalised ALT group (bTR). In the normalised group, 23 met the criteria for $\mathrm{BR}$; all BR patients showed ALT normalisation during IFN treatment. Clinical backgrounds of the patients in each group are summarised in table 2. Figure 3 demonstrates the relationship between ALT response and the sequence of the ARE. Amino acid substitution seemed to be permitted only at amino acids 2154, 2155, 2169 , and 2171 . As the number of amino acids that are different from those of $\mathrm{HCV}-1 \mathrm{~b}$ (defined as "substitution number") increases, it is more likely that an ALT response is obtained. Figure 4 shows the relationship between clinical parameters and amino acid sequences were performed by logistic regression analyses (univariate or multiple as appropriate) with the JMP program (v. 3.1, SAS Institute, Cary, North Carolina, USA). 
Table 2 Clinical backgrounds of the 82 patients

\begin{tabular}{lc}
\hline Variable & \\
\hline Age $(\mathrm{y})$ & $47.7(10.3)$ \\
Sex $(\mathrm{M} / \mathrm{F})$ & $56 / 26$ \\
Pretreatment serum ALT $(\mathrm{U} / \mathrm{l})$ & $100.2(59.6)$ \\
F factor & $1.80(0.74)$ \\
Serum HCV-RNA load $(\mathrm{Meq} / \mathrm{ml})$ & $5.0[<0.5-40]$ \\
Mutation number in ISDR & $1.0[0-6]$
\end{tabular}

Values are number, mean (SD), or median [range].

ALT, alanine aminotransferase; HCV, hepatitis C virus; ISDR, interferon sensitivity determining region.

between the rate of ALT normalisation and substitution number in the ARE. The substitution number ranged from 0 to 4 . Clearly, ALT response rates are positively correlated with the substitution number in the ARE ( $p=0.004$ on simple $\chi^{2}$ test).

Additionally, the relationship between substitution number in the ARE and vTR - that is, the disappearance of serum HCV-RNA-was analysed. While bTR frequently coincided with vTR ( $p<0.0001, \chi^{2}$ test), dissociation between the two phenomena was also observed (table 3 ) in some patients. In particular, bTR preceded $\mathrm{BR}$ in all $23 \mathrm{BR}$ patients (by definition) while vTR preceded BR in only 17 patients.

Factors possibly associated with ALT normalisation were analysed by univariate analysis with substitution number in the ARE, substitution number in the ISDR, serum HCV-RNA titre, age, $\mathrm{F}$ factor (according to international criteria $^{18}$ ), and pretreatment serum ALT value as independent variables (table $4 \mathrm{~A}$ ). Using this analysis, only the substitution number in the ARE was extracted as a statistically significant factor $(p=0.0003)$. Subsequent multiple logistic regression analysis revealed that the substitution number in the ARE was the only independent factor for normalisation of ALT $(p=0.0007)$ (table 4B). Of the above mentioned variables, only the substitution number in the ISDR correlated with the substitution number in the ARE $(p=0.003)$. The relationship between substitution number in the ARE and $B R$ did not reach statistical significance.

Finally, the substitution numbers in the ARE were determined in 11 patients who received IFN therapy and were CRs. However, no relationship was found between serum ALT values during IFN treatment and substitution number in the ARE. The substitution number in the ARE also ranged from 0 to 4 in this group. The amino acid sequences of the ARE in HCV-2a (corresponding to amino acids 2158 to 2176 of HC-J6; five amino acid substitutions are present compared with HCV-J) and $\mathrm{HCV}-2 \mathrm{~b}$ (corresponding to amino acids 2158 to $2176 \mathrm{HC}-\mathrm{J} 8$; six amino acid substitutions are present compared with HCV-J) were also determined in six patients with $\mathrm{HCV}-2 \mathrm{a}$ infection and 10 with HCV-2b, all of whom received IFN therapy and were NRs but showed ALT normalisation during IFN therapy and were TRs. However, only one amino acid substitution was observed in HCV-2a (T2176M) in five of six patients, and no amino acid polymorphism was observed in this region of $\mathrm{HCV}-2 \mathrm{~b}$.

\section{Discussion}

In this study, the relationship between the pattern of ALT response to IFN therapy and HCV sequences was analysed. We found that amino acid substitutions in NS5A (amino acids 2154-2172, a region we have named the ALT response related element (ARE)) that differ from the prototype HCV-1b sequence, were strongly associated with normalisation of ALT during IFN therapy.

Variations in viral genomic sequence and clinical presentation have been associated with some RNA viruses, such as pestiviridae (including HCV) and flaviviridae. In encephalitogenic flaviviruses, such as yellow fever virus, Japanese encephalitis virus, or tick borne encephalitis virus, attenuation of passaged viruses was consistently associated with amino acid changes in protein $\mathrm{E}$, and a single amino acid change in a critical determinant of protein $E$ can be sufficient for loss of neuroinvasiveness. ${ }^{19}$ However, studies addressing this issue in $\mathrm{HCV}$ are rare. We have previously shown in the natural course of chronic hepatitis $\mathrm{C}$ that time related amino acid substitutions in the NS5A/ NS5B protein of $\mathrm{HCV}$ are associated with changes in the activity of hepatitis ${ }^{15}$; this is the only report of which we are aware associating HCV genomic sequences with activity of hepatitis. Similarly, the present study shows a relationship between $\mathrm{HCV}$ sequences and the course of serum ALT levels, which reflects hepatitis activity during IFN treatment. To date, differences in hepatitis activity during the natural course of chronic hepatitis $\mathrm{C}$ in different patients was analysed mainly from the point of view of the genetic background of the host. For example, HLA-DR5 was reported to be associated with anti-HCV positive symptom free individuals, ${ }^{20}$ and TAP $2{ }^{\star} 0103$ (transporter associated with antigen processing 2 ) has been associated with patients with persistently normal ALT values. ${ }^{21}$ However, our results indicate that viral sequences may also be important.

We have previously characterised the ISDR sequence at positions $2209-2248$ of the NS5A protein of $\mathrm{HCV}$ as a virological determinant predicting the efficacy of IFN therapy. ${ }^{10}{ }^{11}$ Although the genomic region of the ARE is different from that of the ISDR, the ISDR sequence in $\mathrm{HCV}$ is also associated with a clinical presentation of chronic hepatitis C. In Japanese patients, the ISDR sequence is useful for predicting whether a complete response will be achieved ${ }^{11}$ although there appears to be some controversy. Similarly, the ARE sequence may be useful for predicting whether ALT normalisation will occur, although a prospective study is necessary to establish this.

The ISDR sequence is located about 60 amino acids downstream of the ARE, and the number of amino acid substitutions in these two regions was correlated. Although it cannot be concluded from this study that there are any functional relationships between the ARE and the ISDR, it is possible and they may operate together. While Duverlie et al recently suggested that substitution at amino acid 2169 is related to sensitivity to IFN therapy, ${ }^{22}$ we could 

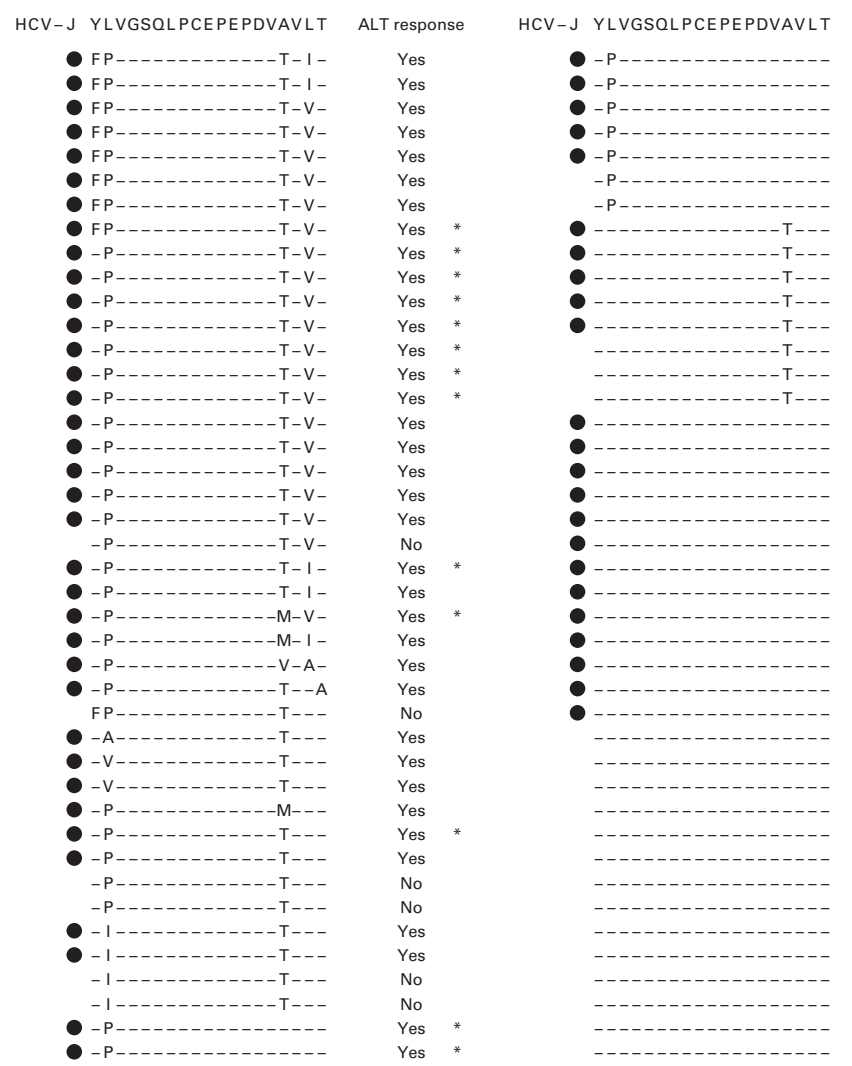

ALT response
Yes
Yes
Yes
Yes
Yes
No
No
Yes
Yes
Yes
Yes
Yes
No
No
No
Yes
Yes
Yes
Yes
Yes
Yes
Yes
Yes
Yes
Yes
Yes
Yes
Yes
Yes
No
No
No
No
No
No
No
No
No
No
No
No
No
No

Figure 3 Relationship between amino acid sequences in the alanine aminotransferase (ALT) response related element (ARE) in 82 patients. Amino acid residues from 2154 to 2172 are shown. Amino acid residues identical to those of $H C V-\mathcal{7}$ are shown as "-”. Filled circles (•) indicates that serum ALT values normalised during interferon therapy. *Biochemical responders.
Table 3 Relationships between alanine aminotransferase (ALT) response and virological transient responder (vTR) among the 82 patients who received interferon therapy (number of patients)

\begin{tabular}{lll}
\hline & $v T R(n=50)$ & $v N R(n=32)$ \\
\hline ALT normalisation (n) & & \\
bTR (59) & 44 & 15 \\
BR (23) & 17 & 6 \\
bNR (23) & 6 & 17
\end{tabular}

$\mathrm{p}<0.0001, \chi^{2}$ test (total bTR $v$ bNR).

vNR, virological non-responders; bTR, biochemical transient responder; $\mathrm{BR}$, biochemical responder; bNR, biochemical nonresponder.

acid substitutions in the ARE sequence awaits further in vitro study, the L2155P substitution may have some impact on transactivator activity because it alters the polarity of the amino acid. Indeed, we have shown that amino acid mutations in the acidic domains attenuate the transactivator activity of the NS5A. ${ }^{24}$ Another study suggested that there is a possible alternative processing site of the NS5A protein at amino acid $2172^{27}$ by NS3 protease. Processing at this site produces a truncated NS5A protein that can translocate into the nucleus and exhibit transactivator activity. Substitutions at amino acids 2169,2171 , and 2172 may alter the processing efficiency and influence this putative NS5A function.

There was a strong correlation between bTR during IFN therapy and vTR, although inconsistent cases were also observed. While the relationship between substitutions in the ARE and bTR seemed to be more direct than vTR, the collinearity of bTR and VTR made a multivariate analysis difficult for discrimination; a larger number of samples are needed to address this point.

Alternatively, profound inhibition of HCVRNA replication in hepatic tissue during IFN administration may cause suppression of hepatocellular injury resulting in decreased ALT levels. If so, the ARE may determine the efficacy of $\mathrm{HCV}$ replication during IFN treatment. Hepatocyte injury in chronic hepatitis $\mathrm{C}$ is thought to be caused by cytotoxic $\mathrm{T}$ lymphocytes (CTL) against virus derived peptide presented on the hepatocyte surface in HLA molecules. Therefore, profound suppression of HCV replication by IFN may cause the disappearance of such viral epitopes resulting in a decrease in hepatocyte injury. Also, the ARE may directly determine the activity of hepatitis during IFN therapy. For example, a specific ARE sequence could modulate HLA expression or peptide presentation, which is usually enhanced by IFN, resulting in decreased hepatocellular damage by CTL. In fact, a recent report suggested that polymorphism in a peptide transporter involved in antigen presentation is associated with hepatitis activity. ${ }^{22}$

It has been suggested that the long term prognosis may improve, even in patients who did not become CRs with IFN therapy. Kasahara et al showed in a cohort study of 1022 patients that the cumulative incidence of HCC was significantly higher in those patients who

showed persistently abnormal ALT values. ${ }^{7}$ A by the ARE and adjacent regions has not in the acidic domain 1 , which is importan the transactivator activity of NS5A. ${ }^{24-26} \mathrm{Al}-$ though the functional significance of amino 
Table 4 Factors contributing to the alanine aminotransferase (ALT) response to interferon therapy

\begin{tabular}{llll}
\hline Variable & p Value & Odds ratio & 95\% CI \\
\hline (A) Univariate analysis & & & \\
Mutation numbers in the ARE & 0.0003 & 37.4 & $6.3-333$ \\
Mutation numbers in the ISDR & 0.078 & 59.7 & $1.02-9300$ \\
Pretreatment serum HCV-RNA $(\mathrm{Meq} / \mathrm{ml})$ & 0.128 & 0.22 & $0.04-1.53$ \\
Age & 0.177 & 0.23 & $0.02-1.86$ \\
F factor & 0.250 & 0.47 & $0.12-1.73$ \\
Pretreatment serum ALT value $(\mathrm{IU} / \mathrm{l})$ & 0.492 & 0.48 & $0.06-4.23$ \\
(B) Multivariate analysis & & & \\
Mutation numbers in the ARE & 0.0007 & 31.0 & $5.03-286$ \\
Mutation numbers in the ISDR & 0.378 & 5.30 & $0.23-471$ \\
Pretreatment serum HCV-RNA $(\mathrm{Meq} / \mathrm{ml})$ & 0.191 & 0.17 & $0.01-2.26$ \\
Age & 0.195 & 0.25 & $0.03-2.00$
\end{tabular}

$\overline{\text { ISDR, interferon sensitivity determining region; ARE, ALT response related element; HCV, }}$ hepatitis C virus; CI, confidence inerval.

follow up study of a large number of patients ${ }^{6}$ demonstrated a reduced incidence rate of HCC in BRs. More recently, we showed that patients who were vTRs also had a lower probability of developing HCC in a prospective analysis. These findings suggest that the benefit of IFN therapy may not be observed only in BRs (those whose ALT course resembles fig 1C), but also in bTRs who do not fulfill the criteria for BR (those whose ALT course resembles fig $1 \mathrm{~B}$ ). This long term effect of IFN therapy may be secondary to a decrease in the progression of liver disease by reducing the grade of inflammatory activity and stage of fibrosis $^{828}$ or direct ablation of precancerous cells by an anti-oncogenic effect of interferon regulatory factor 1 induced by $I F N{ }^{28}$

Although re-biopsy after IFN therapy was not performed in this study, it is reasonable to postulate that the reduction in inflammatory activity also occurred in our subjects showing normalised serum ALT values following IFN treatment. As a consequence, a virological marker to identify a group of patients who have a better long term prognosis after IFN therapy was suggested in this study, which is effective even in those whose serum HCV could not be eradicated by IFN.

In conclusion, a sequence element (the ARE) in the NS5A protein of $\mathrm{HCV}-1 \mathrm{~b}$ was identified that was significantly associated with ALT normalisation or transient serum HCVRNA disappearance during IFN therapy in those who did not become CRs. The possibility that patients with substitutions in the ARE may have a better long term prognosis was suggested, and indicates that the ARE sequence could be a useful marker for selection of candidates for IFN therapy. Although the biological significance of the mutations in the ARE is currently unknown, an explanation may contribute to our understanding of the underlying mechanism causing hepatocellular injury in chronic hepatitis C.

This work was supported in part by the Program for Promotion of Fundamental Studies in Health Sciences of the Organisation for Drug ADR Relief, R\&D Promotion and Product Review of Japan, and a grant in aid $(08457164)$ by the Japanese Ministry of Education, Sciences, Culture, and Sports.
1 Choo QL, Kuo G, Weiner AJ, et al. Isolation of a cDNA Choo QL, Kuo G, Weiner AJ, et al. Isolation of a cDNA clone derived from a blood-borne non-A,

2 Major ME, Feinstone SM. The molecular virology of hepatitis C. Hepatology 1997;25:1527-38.

3 Tanaka T, Kato N, Cho MJ, et al. Structure of the 3' terminus of the hepatitis of hepatitis $\mathrm{C}$ virus genome. $\mathrm{F}$ Virol 1996;70:3307-12.

4 Kiyosawa K, Sodeyama T, Tanaka E, et al. Interrelationship of blood transfusion, non-A, non-B hepatitis and hepatocellular carcinoma: analysis by detection of antibody to hepatitis C virus. Hepatology 1990;12:671-5.

5 Hoofnagle JK, Bisceglie AM. The treatment of chronic viral hepatitis. N Engl f Med 1997;336:347-56.

6 Ikeda K, Saitoh S, Chayama K, et al. Effect of interferon therapy on hepatocellular carcinogenesis in patients with chronic hepatitis type C: a long-term observation study of 1,643 patients using statistical bias correction with proportional hazard analysis. Hepatology 1999;29:1124-30.

7 Kasahara A, Hayashi N, Mochizuki K, et al. Risk factors for hepatocellular carcinoma and its incidence after interferon treatment in patients with chronic hepatitis C. Osaka Liver Disease Study Group. Hepatology 1998;27:1394-402.

8 Nishiguchi S, Kuroki T, Nakatani S, et al. Randomized trial of effects of interferon- $\alpha$ on incidence of hepatocellular carcinoma in chronic active hepatitis C with cirrhosis. Lancet 1995;346:1051-5.

9 Poynard T, Leroy V, Cohard M, et al. Meta-analysis of interferon randomized trials in the treatment of viral hepatitis $C$. Effects of dose and duration. Hepatology 1996;24:778-89.

10 Enomoto N, Sakuma I, Asahina Y, et al. Comparison of fulllength sequences of interferon-sensitive and resistant hepatitis $C$ virus 1 b. $\mathcal{F}$ Clin Invest 1995;96:224-30.

11 Enomoto N, Sakuma I, Asahina Y, et al. Mutations in the nonstructural protein $5 \mathrm{~A}$ gene and response to interferon in patients with chronic hepatitis $\mathrm{C}$ virus $1 \mathrm{~b}$ infection. $N$ Engl f Med 1996;334:77-81.

12 Okamoto $\mathrm{H}$, Sugiyama Y, Okada K, et al. Typing hepatitis C virus by polymerase chain reaction with type-specific primers: application to clinical surveys and tracing primers: application to clinical surveys a

13 Simmonds P, Alberti A, Alter HJ, et al. A proposed system for the nomenclature of hepatitis C viral genotypes. Hepatology 1994;19:1321-4.

14 Lau JY, Davis GL, Kniffen J, et al. Significance of serum hepatitis C virus RNA levels in chronic hepatitis C (erratum appears in Lancet 1993;342:504). Lancet 1993; 341:1501-4

15 Nagayama K, Kurosaki M, Enomoto N, et al. Time-related changes of full-length hepatitis $\mathrm{C}$ virus sequences and hepatitis activity. Virology 1999;263:244-53.

16 Nagayama K, Kurosaki M, Enomoto N, et al. Characteristics of hepatitis $\mathrm{C}$ viral genome associated with disease progression. Hepatology 2000;31:145-50.

17 Kato N, Hijikata M, Ootsuyama Y, et al. Molecular cloning of the human hepatitis C virus genome from Japanese patients with non-A, non-B hepatitis. Proc Natl Acad Sci patients with non-A,
USA 1990;87:9524-8.

18 Desmet VJ, Gerber M, Hoofnagle JH, et al. Classification of chronic hepatitis: diagnosis, grading and staging. Hepatology 1994;19:1513-20.

19 McMinn PC. The molecular basis of virulence of the encephalitogenic flaviviruses. F Gen Virol 1997;78:271122.

20 Peano G, Menardi G, Ponzetto A, et al. HLA-DR5 antigen. A genetic factor influencing the outcome of hepatitis $C$ virus infection? Arch Intern Med 1994;154:2733-6.

21 Kuzushita N, Hayashi N, Kanto T, et al. Involvement of transporter associated with antigen processing 2 (TAP2) gene polymorphism in hepatitis C virus infection. Gastroenterology 1999;116:1149-54.

22 Duverlie G, Khorsi H, Castelain S, et al. Sequence analysis of the NS5A protein of European hepatitis $C$ virus $1 \mathrm{~b}$ isoof the NS5A protein of European hepatitis C virus 1b iso-
lates and relation to interferon sensitivity. F Gen Virol 1998; 79:1373-81.

23 Nakano I, Fukuda Y, Nakano S, et al. Why is the interferonsensitivity determining region (ISDR) system useful in Japan? F Hepatol 1999;30:1014-22.

24 Fukuma T, Enomoto N, Marumo F, et al. The mutations in the interferon sensitivity determining region of hepatitis $\mathrm{C}$ virus and the transcriptional activity of NS5A protein. Hepatology 1998;28:1147-53.

25 Kato N, Lan KH, Ono-Nita SK, et al. Hepatitis C virus nonstructural region $5 \mathrm{~A}$ is a potent transcriptional activator. $\mathcal{F}$ Virol 1997;71:8856-9.

26 Tanimoto A, Ide $\mathrm{Y}$, Arima $\mathrm{N}$, et al. The amino terminal deletion mutants of hepatitis $C$ virus nonstructural protein NS5A function as transcriptional activators in yeast. Biochem Biophys Res Comm 1997;236:360-4.

27 Markland W, Petrillo RA, Fitzgibbon M, et al. Purification and characterization of the NS3 serine protease domain of hepatitis C virus expressed in Saccharomyces cerevisiae. $\mathcal{F}$ Gen Virol 1997;78:39-43.

28 Camma C, Ginuta M, Linea C, et al. The effect of interferon on the liver in chronic hepatitis C: a quantitative evaluation of histology by meta-analysis. F Hepatol 1997;26:1187-99. 